\title{
Diagnostic Utility of Blood Volume Monitoring in Hemodialysis Patients
}

\author{
Rajiv Agarwal, $M D,{ }^{1,2}$ Ken Kelley, $P h D,{ }^{3}$ and Robert P. Light, $B S^{1,2}$
}

\begin{abstract}
Background: Assessment of volume state is difficult in hemodialysis patients. Whether continuous blood volume monitoring can improve the assessment of volume state is unclear.

Study Design: Diagnostic test study.

Settings \& Participants: Asymptomatic long-term hemodialysis patients $(n=150)$ in 4 universityaffiliated hemodialysis units.

Index Tests: Ultrafiltration rate (UFR) divided by postdialysis weight (UFR index), slopes of relative blood volume (RBV), RBV slope corrected for UFR and weight (volume index).

Reference Tests: Dialysis-related symptoms and echocardiographic signs of volume excess and volume depletion, assessed by using inferior vena cava (IVC) diameter after dialysis and its collapse on inspiration. Volume excess was defined as values in the upper third of IVC diameter or lower third of IVC collapse on inspiration. Volume depletion was defined as values in the lower third of IVC diameter or upper third of IVC collapse on inspiration.

Results: Mean UFR was $8.3 \pm 3.8(\mathrm{SD}) \mathrm{mL} / \mathrm{h} / \mathrm{kg}$. Mean RBV slope was $-2.32 \% \pm 1.50 \% / \mathrm{h}$. Mean volume index was $-0.25 \% \pm 0.17 \% / \mathrm{h} / \mathrm{mL} / \mathrm{h}$ ultrafiltration $/ \mathrm{kg}$. Volume index provided the best fit of observed RBV slopes. Volume index was related to dizziness, the need to decrease UFR, and placement in Trendelenberg position. RBV and volume index, but not UFR index, were related to echocardiographic markers of volume excess and depletion. Areas under the receiver operating characteristic curve to predict volume excess were 0.48 (95\% confidence interval $[\mathrm{Cl}], 0.33$ to 0.63$)$ for UFR index, 0.71 ( $95 \% \mathrm{Cl}, 0.60$ to 0.83$)$ for RBV slope, and $0.73(95 \% \mathrm{Cl}, 0.59$ to 0.86$)$ for volume index. Areas under the receiver operating characteristic curve to predict volume depletion were $0.56(95 \% \mathrm{Cl}$, 0.38 to 0.74$)$ for UFR index, $0.55(95 \% \mathrm{Cl}, 0.38$ to 0.72$)$ for RBV slope, and $0.62(95 \% \mathrm{Cl}, 0.48$ to 0.76$)$ for volume index.

Limitations: Dialysis-related symptoms and echocardiographic findings are not validated measures of volume. Our results were not adjusted for demographic or clinical characteristics; performance characteristics of the indices may differ across populations.

Conclusions: Volume index appears to be a novel marker of volume, but requires validation studies, and its utility needs to be tested in clinical trials.

Am J Kidney Dis 51:242-254. (c) 2008 by the National Kidney Foundation, Inc.
\end{abstract}

INDEX WORDS: Hemodialysis; blood volume monitoring; echocardiograms; volume overload; intradiaIytic hypotension; diagnostic test studies.

$\mathbf{O}$ ptimization of volume is a key component of the management of hemodialysis patients $^{1}$ and was the subject of numerous investigations. ${ }^{2-6}$ Assessment of volume state in these patients is central to prescribing volume removal, and volume control is believed to be important to judge the adequacy of hemodialysis. $^{7}$ An accurate prescription can improve toler-

From the ${ }^{1}$ Department of Medicine, Division of Nephrology, Indiana University School of Medicine; ${ }^{2}$ Richard L. Roudebush VA Medical Center, Indianapolis; and ${ }^{3}$ Inquiry Methodology Program, Indiana University, Bloomington, IN.

Received June 5, 2007. Accepted in revised form October 28 , 2007. Originally published online as doi: 10.1053/j.ajkd.2007.10.036 on December 28, 2007.

Address correspondence to Rajiv Agarwal, MD, Professor of Medicine, VAMC, $111 \mathrm{~N} 1481$ West 10th St, Indianapolis IN 46202. E-mail: ragarwal@iupui.edu

(C) 2008 by the National Kidney Foundation, Inc.

0272-6386/08/5102-0010\$34.00/0

doi:10.1053/j.ajkd.2007.10.036 ance and adherence to dialysis therapy and avoid the long-term consequences of volume excess. ${ }^{8}$ Clinical experience suggests that keeping the patient "too wet" may lead to poor long-term outcomes, and "too dry," to poor tolerance. A fluid removal rate that exceeds the refilling rate of the intravascular volume may result in hypotension, which continues to be a vexing problem for which new therapies are being developed. ${ }^{9-11}$ Importantly, dialysis-related hypotension is associated with increased mortality. ${ }^{12,13}$ However, inadequate removal of fluid may lead to a longterm increase in cardiac output, compensatory increase in systemic vascular resistance, and hypertension. ${ }^{8,14,15}$ In turn, this can lead to cardiovascular morbidity and mortality. ${ }^{16}$ Epidemiological studies suggested that expanded extracellular fluid volume in hemodialysis patients was associated with increased all-cause mortality. ${ }^{17,18}$

Intradialytic blood volume monitoring (IBVM) is a commercially available technology that can 
measure relative blood volume (RBV) changes during hemodialysis. ${ }^{19-21}$ One such instrument for IBVM uses photo-optical technology to noninvasively measure absolute hematocrit and percentage of blood volume change in real time. ${ }^{21}$ The slopes of RBV displayed on the screen indicate the rate of RBV decrease and have largely been were used to gauge hemodynamic stability during dialysis, with mixed success. ${ }^{22-24}$ Although IBVM can be performed safely and inexpensively and has the potential to improve volume control, ${ }^{25,26}$ no normative data are available; thus, the optimal level of fluid removal guided by blood volume monitoring is unknown. $^{27}$

The purpose of this study is to develop a better marker of volume in hemodialysis patients. Accordingly, we compared 3 markers of volume excess with outcome parameters that included intradialytic signs and symptoms of hypotension and interventions and echocardiographically assessed blood volume. The 3 markers of volume were ultrafiltration rate (UFR) indexed for body weight, which we call UFR index; RBV slope; and RBV slope adjusted for UFR index, which we call volume index. We designed this study to assess the interrelationships between IBVM intradialytic symptoms and markers of excess volume on echocardiograms.

\section{METHODS}

\section{Conceptual Model}

To conceptualize volume compartments, we formulated a model to review the physiological characteristics of volume removal during hemodialysis (see Appendix for details and Table 1 for outline). The amount of ultrafiltration prescribed dictates the stress placed on intravascular volume. More accurately, it is not ultrafiltration by itself, but UFR cor- rected for body weight (a reflection of total-body water) that produces the volume stress. We call this the ultrafiltration index. In response to the UFR index, hematocrit change in the intravascular compartment and the magnitude of this is measured by means of RBV slope. RBV slope is a function of fluid removal rate (UFR index) and plasma refill rate. Adjustment of RBV slope for UFR index would be an index of the plasma refill rate. Because UFR index is known for each patient, RBV slope corrected for UFR index, the volume index, is simply a reflection of the latent volume pool and the ability of this pool to replenish the intravascular compartment. Using this model, it is possible to define the volume marker being tested. Table 1 lists the 3 indices.

\section{Definitions of Volume Markers \\ UFR Index}

Total amount of ultrafiltration (milliliters) was calculated for each patient based on the dialysis machine reading. Total volume of ultrafiltration was divided by dialysis time in hours to calculate UFR. UFR divided by postdialysis weight (kilograms) provided UFR index. UFR index $=$ ultrafiltration $(\mathrm{mL}) /$ dialysis time $(\mathrm{h}) /$ postdialysis weight $(\mathrm{kg})$.

\section{RBV Slope}

The slope of RBV over time was calculated as percentage per hour by using a straight-line change model, described in the data analysis section.

\section{Volume Index}

RBV slope was adjusted for UFR index to provide volume index. This parameter, as discussed, is suggested to be a marker of vascular refilling rate.

\section{Subjects}

This is a cross-sectional study performed at 4 dialysis units in Indianapolis affiliated with Indiana University during 2 consecutive weeks. One unit was at the Veterans Administration (VA) Hospital, but the other 3 were VAunaffiliated units. Patients 18 years or older who had been on long-term hemodialysis therapy for more than 3 months and were free of vascular, infectious, or bleeding complication within 1 month were enrolled in the study. Those who missed 2 or more hemodialysis treatments during 1 month,

Table 1. Description of Volume Parameters in Hemodialysis Patients

\begin{tabular}{|c|c|c|c|}
\hline & Ultrafiltration Rate Index & $\begin{array}{l}\text { Relative Blood } \\
\text { Volume Slope }\end{array}$ & Volume Index \\
\hline $\begin{array}{l}\text { Independent } \\
\text { variables }\end{array}$ & $\begin{array}{l}\text { Ultrafiltration, dialysis } \\
\text { time, postdialysis } \\
\text { weight }\end{array}$ & Hematocrit, time & $\begin{array}{l}\text { Ultrafiltration, dialysis time, postdialysis } \\
\text { weight, hematocrit, time }\end{array}$ \\
\hline $\begin{array}{l}\text { Volume } \\
\text { compartment }\end{array}$ & $\begin{array}{l}\text { Volume stress to } \\
\text { intravascular } \\
\text { compartment }\end{array}$ & $\begin{array}{l}\text { Relative change in } \\
\text { intravascular } \\
\text { volume }\end{array}$ & Relative change in interstitial fluid volume \\
\hline Equipment & $\begin{array}{l}\text { Dialysis machine readout, } \\
\text { watch, weighing scales }\end{array}$ & $\begin{array}{l}\text { Continuous blood } \\
\text { volume monitor }\end{array}$ & $\begin{array}{l}\text { Continuous blood volume monitor, dialysis } \\
\text { machine readout, watch, weighing } \\
\text { scales }\end{array}$ \\
\hline
\end{tabular}


abused drugs, had chronic atrial fibrillation, or had body mass index of $40 \mathrm{~kg} / \mathrm{m}^{2}$ or greater were excluded. Patients who had a change in dry weight or antihypertensive drug therapy within 2 weeks also were excluded. All patients underwent standard thrice-weekly dialysis.

Anthropometric and demographic characteristics were recorded. Echocardiography was performed by 1 echocardiographer immediately after the termination of dialysis within an hour of the end of dialysis treatment.

A total of 150 long-term hemodialysis patients were recruited between September 2003 and February 2005. The sample was drawn from 355 patients on thrice-weekly hemodialysis therapy from 4 dialysis units affiliated with Indiana University, of which $48 \%$ were women, $36 \%$ had diabetes, and $72 \%$ were black. Because fewer white patients were recruited, the racial make-up of the 126 patients who were screened, but did not participate, were analyzed. Of these, 41 blacks (76\%), $12(22 \%)$ whites, and 1 (2\%) Asian met the recruitment criteria, but refused participation. Fiftyfive blacks (76\%), 15 whites (21\%), and 2 Asians (3\%) did not meet 1 of the inclusion or exclusion criteria. Because 27 of $126(21 \%)$ did not meet eligibility or refused participation, our sample included more black participants than the overall composition from which the sample was derived.

The study was approved by the Institutional Review Board of Indiana University and Research and Development Committee of the Roudebush VA Medical Center, Indianapolis, and all subjects gave written informed consent.

\section{Predictors}

\section{Intradialytic Blood Volume Monitoring}

All 150 patients underwent successful IBVM, which was performed once during the 2-week period. Crit-Line III-TQA (Hemametrics, Salt Lake City, UT) is a fluidmanagement and access-monitoring tool approved by the Food and Drug Administration. It incorporates photooptical technology to noninvasively measure absolute hematocrit, percentage of blood volume change, and continuous oxygen saturation. ${ }^{21}$ An autoscaling screen

Table 2. Clinical Characteristics of the Study Population

\begin{tabular}{|c|c|c|c|c|}
\hline Clinical Characteristic & $\mathrm{n}=150$ & Echocardiogram $(n=135)$ & No Echocardiogram $(n=15)$ & $P$ \\
\hline Age $(y)$ & $55.8 \pm 13.5$ & $55.5 \pm 1.1$ & $58.4 \pm 5.1$ & 0.4 \\
\hline Men & $94(63)$ & $84(62)$ & $10(67)$ & 0.7 \\
\hline Race & & & & 0.03 \\
\hline White & $13(9)$ & $9(7)$ & $4(27)$ & \\
\hline Black & $135(90)$ & $124(92)$ & $11(73)$ & \\
\hline Other & $2(1)$ & $2(1)$ & $0(0)$ & \\
\hline Predialysis weight (kg) & $81.8 \pm 19.5$ & $81.5 \pm 18.9$ & $84.5 \pm 24.8$ & 0.6 \\
\hline Postdialysis weight (kg) & $79.1 \pm 19.0$ & $78.8 \pm 1.6$ & $81.8 \pm 24.4$ & 0.6 \\
\hline Ultrafiltration volume $(\mathrm{mL})$ & $2563 \pm 1273$ & $2589 \pm 1310$ & $2310 \pm 843$ & 0.4 \\
\hline Predialysis SBP $(\mathrm{mm} \mathrm{Hg})$ & $143.0 \pm 22.4$ & $141.9 \pm 22.0$ & $152.3 \pm 24.3$ & 0.09 \\
\hline Predialysis DBP $(\mathrm{mm} \mathrm{Hg})$ & $75.0 \pm 13.7$ & $74.9 \pm 13.3$ & $78.1 \pm 17.4$ & 0.4 \\
\hline Predialysis heart rate (beats/min) & $77.7 \pm 11.2$ & $78.0 \pm 11.2$ & $75.0 \pm 10.9$ & 0.3 \\
\hline Postdialysis SBP $(\mathrm{mm} \mathrm{Hg})$ & $121.4 \pm 21.7$ & $120.5 \pm 20.9$ & $130.0 \pm 17.1$ & 0.1 \\
\hline Postdialysis DBP $(\mathrm{mm} \mathrm{Hg})$ & $69.9 \pm 13.1$ & $69.5 \pm 12.5$ & $73.3 \pm 17.2$ & 0.3 \\
\hline Postdialysis heart rate (beats/min) & $80.0 \pm 11.3$ & $79.7 \pm 10.8$ & $78.1 \pm 15.4$ & 0.6 \\
\hline Body mass index $\left(\mathrm{kg} / \mathrm{m}^{2}\right)$ & $27.0 \pm 6.1$ & $26.6 \pm 6.2$ & $27.9 \pm 5.8$ & 0.4 \\
\hline Years of dialysis & $4.0 \pm 3.0$ & $4.0 \pm 3.0$ & $4.2 \pm 2.8$ & 0.8 \\
\hline Cause of end-stage renal disease & & & & 0.9 \\
\hline Diabetes mellitus & 47 (31) & $43(32)$ & $4(27)$ & \\
\hline Hypertension & $83(55)$ & $74(55)$ & $9(60)$ & \\
\hline Glomerulonephritis & $9(6)$ & $8(6)$ & $1(7)$ & \\
\hline Obstruction & $1(<1)$ & $1(1)$ & $0(0)$ & \\
\hline Other & $10(7)$ & $9(7)$ & $1(7)$ & \\
\hline Current smoker & $56(37)$ & $52(39)$ & $4(27)$ & 0.4 \\
\hline Cardiovascular disease & $71(47)$ & $63(47)$ & $8(53)$ & 0.6 \\
\hline $\mathrm{Kt} / \mathrm{V}$ & $1.6 \pm 0.4$ & $1.6 \pm 0.4$ & $1.6 \pm 0.4$ & 0.7 \\
\hline Albumin (g/dL) & $3.8 \pm 0.4$ & $3.8 \pm 0.4$ & $3.7 \pm 0.4$ & 0.1 \\
\hline Hemoglobin (g/dL) & $12.4 \pm 1.5$ & $12.5 \pm 1.5$ & $11.9 \pm 1.5$ & 0.2 \\
\hline \multicolumn{5}{|l|}{ Predictor variables } \\
\hline Ultrafiltration rate index $(\mathrm{mL} / \mathrm{h} / \mathrm{kg})$ & $8.3 \pm 3.8$ & $8.4 \pm 3.9$ & $7.7 \pm 3.0$ & 0.5 \\
\hline Relative blood volume $(\% / \mathrm{h})$ & $-2.32 \pm 1.50$ & $-2.33 \pm 1.53$ & $-2.27 \pm 1.2$ & 0.9 \\
\hline $\begin{array}{l}\text { Volume index } \\
\qquad\left(\% / \mathrm{h} / \mathrm{mL} / \mathrm{h}_{\text {ultrafiltration }} / \mathrm{kg}\right)\end{array}$ & $-0.277 \pm 0.18$ & $-0.276 \pm 0.19$ & $-0.293 \pm 0.11$ & 0.7 \\
\hline
\end{tabular}

Note: Values expressed as mean \pm SD or number (percent). To convert albumin in $\mathrm{g} / \mathrm{dL}$ to $\mathrm{g} / \mathrm{L}$, multiply by 10 ; hemoglobin in $\mathrm{g} / \mathrm{dL}$ to $\mathrm{g} / \mathrm{L}$ multiply by 10 . 
displays simultaneous graphic output of blood volume change versus time, as well as alphanumeric output of hematocrit. Measurements are made every 20 seconds throughout the duration of the hemodialysis treatment. Hematocrit measurements made by the machine were validated against hematocrits measured by using centrifugation. ${ }^{20}$ We exported the machine-stored time and hematocrit data to a relational database for further analysis. To analyze the rebound in RBV, we turned ultrafiltration off 15 minutes before the end of dialysis.

\section{Outcomes}

\section{Assessment of Intradialytic Hypotension}

During 2 consecutive weeks, each hemodialysis patient participating in the study was prospectively questioned by research technicians regarding the presence or absence of various intradialytic symptoms, such as cramps, dizziness, nausea, and headache. Symptoms of hypotension, such as cramps and dizziness, were obtained from patients at the end of each dialysis treatment. Data were collected on structured case report forms. In addition, episodes of dialysis in which

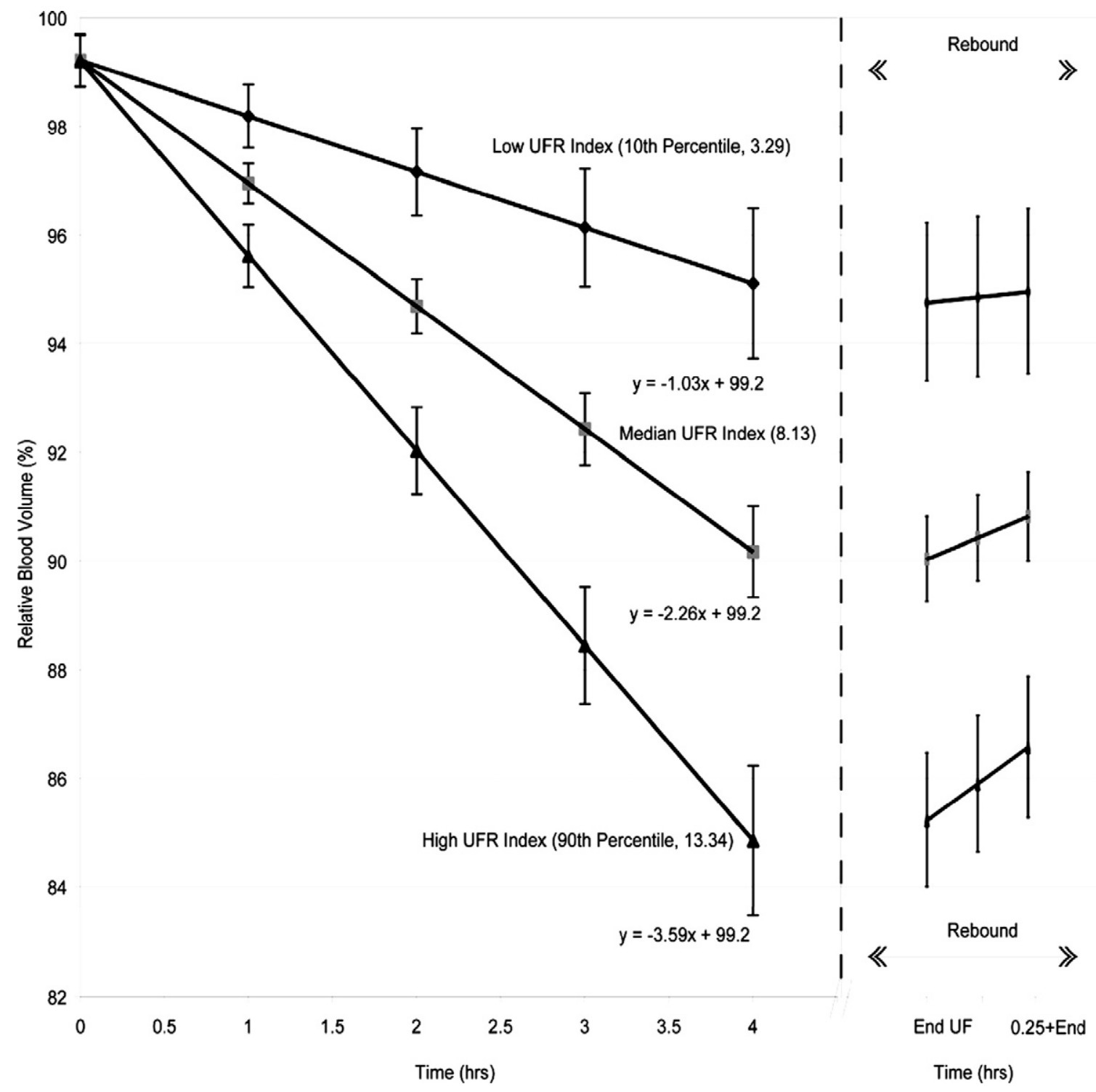

Figure 1. The volume index: relationship of relative blood volume (RBV) slopes as a function of ultrafiltration (UF) rate (UFR) index in different patients. Top line, 10th percentile; middle line, 50th percentile; and bottom line, 90th percentile. RBV slopes increase in steepness from the 10th to 90th percentile. (Right) The relationship of RBV slope rebound in the last 15 minutes of dialysis when UF is stopped. For patients in the 90th percentile, the intercept is lower and rebound is steeper. For patients in the 10th percentile, the intercept is higher and rebound is less steep. 
systolic blood pressure decreased to less than $100 \mathrm{~mm} \mathrm{Hg}$ were recorded. Interventions, such as decreasing UFR, stopping ultrafiltration, need for saline, placement in Trendelenberg position, or early termination of dialysis, were also noted.

\section{Echocardiograms}

Two-dimensional guided M-mode echocardiograms were obtained immediately after a midweek hemodialysis session by using a digital cardiac ultrasound machine (Cypress Acuson; Siemens Medical, Malvern, PA). The postdialysis period was selected for echocardiography because it allows control over the volume state of the patient because it is associated with the least intravascular volume. The day after dialysis would be associated with a variable change in the dimension of the ventricular cavity, depending on the state of volume expansion, and was not chosen for echocardiography. Inferior vena cava (IVC) diameter was measured at the level just below the diaphragm in the hepatic segment by using 2-dimensional guided M-mode echocardiography. IVC diameter was measured just before the $\mathrm{P}$ wave of the electrocardiogram during end-expiration and end-inspiration while avoiding Valsalva-like maneuvers. Collapsibility index was defined as: (maximal diameter on expiration minimal diameter on deep inspiration)/maximal diameter on expiration $\times 100 .{ }^{28}$ All measurements represent an average of 6 consecutive cardiac cycles. Although criteria were developed to detect volume overload and volume depletion, it is unknown whether these thresholds would be valid for post-

dialysis state. ${ }^{28}$ Therefore, tertiles of these measurements were used to define relative volume excess, relative euvolemia, and relative volume depletion. Echocardiograms were either not obtained or IVC measurements were technically challenging in 15 patients. Accordingly, data for echocardiograms represent only 135 patients.

\section{Data Analysis}

In hemodialysis patients, fluid removal results in hemoconcentration. Continuous measurement of hematocrit every 20 seconds allows estimation of fractional change in RBV. RBV was calculated as initial hematocrit divided by instantaneous hematocrit. We transformed the time variable to hours to provide a more meaningful metric of change in RBV such that change was calculated per hour instead of per second.

To test the association of hemodynamic instability and its treatment with UFR index, RBV, or volume index, we counted the number of dialysis treatments during 2 weeks in which the patient experienced cramps; nausea; headache; hypotension, defined as systolic blood pressure less than 100 $\mathrm{mm} \mathrm{Hg}$; or dizziness. We also counted the number of dialysis treatments in which the patient was placed in Trendelenberg position or had ultrafiltration reduced, ultrafiltration discontinued, saline administered, or dialysis terminated early. We used a logistic regression model along with generalized estimating equations for comparing clinical symptoms data collected at these 6 visits with UFR index, $\mathrm{RBV}$, and volume index. This method takes into account correlations among repeated measurements. ${ }^{29}$ Each result is a separate regression model not adjusted for demographic or clinical characteristics.

Tertiles of IVC diameter were created. The middle tertile (IVC diameter, 6.73 to $9.3 \mathrm{~mm} / \mathrm{m}^{2}$ ) defined relative euvolemia. The lower tertile (IVC diameter $<6.73 \mathrm{~mm} / \mathrm{m}^{2}$ ) was used to define volume depletion, and the upper tertile (IVC diameter $>9.3 \mathrm{~mm} / \mathrm{m}^{2}$ ), volume excess.

IVC collapse index in the middle tertile $(21.63 \%$ to $40.23 \%$ ) defined relative euvolemia. The upper tertile (collapse index $>40.23 \%$ ) was used to define volume depletion, and the lower tertile (collapse index $<21.63 \%$ ), volume excess.

Table 3. Intradialytic Symptoms, Signs, and Interventions

\begin{tabular}{|c|c|c|c|c|c|}
\hline & Average \pm SD & $\begin{array}{l}\text { Patients With } \\
\text { Events }\end{array}$ & $\begin{array}{l}\text { Dialysis With } \\
\text { Events }\end{array}$ & $\begin{array}{l}\text { Dialysis With Events in } \\
\text { Those Who Had } \\
\text { Events (\%) }\end{array}$ & $\begin{array}{c}\text { Intraclass Correlation } \\
\text { Coeffcient ( } 95 \% \text { Confidence } \\
\text { Interval) }\end{array}$ \\
\hline \multicolumn{6}{|l|}{ Symptom/sign } \\
\hline Cramps & $1.13 \pm 1.33$ & $83(55)$ & $170(19)$ & 35 & $0.2(0.13-0.26)$ \\
\hline Dizziness & $0.24 \pm 0.64$ & $23(15)$ & $36(4)$ & 27 & $0.17(0.11-0.24)$ \\
\hline \multicolumn{6}{|l|}{ Hypotension $(<100 \mathrm{~mm}$} \\
\hline Hg systolic) & $1.19 \pm 1.70$ & $71(47)$ & $179(20)$ & 43 & $0.43(0.35-0.5)$ \\
\hline Nausea & $0.13 \pm 0.42$ & $15(10)$ & $19(2)$ & 22 & $0.09(0.03-0.14)$ \\
\hline Headache & $0.19 \pm 0.66$ & $15(10)$ & $28(3)$ & 31 & $0.28(0.2-0.35)$ \\
\hline \multicolumn{6}{|l|}{ Interventions } \\
\hline Trendelenberg position & $0.04 \pm 0.28$ & $4(3)$ & $6(0.7)$ & 25 & $0.19(0.16-0.26)$ \\
\hline Ultrafiltration reduced & $0.37 \pm 0.70$ & $40(27)$ & $55(6)$ & 24 & $0.09(0.03-0.14)$ \\
\hline Ultrafiltration stopped & $0.81 \pm 1.07$ & $68(45)$ & $121(14)$ & 30 & $0.13(0.07-0.19)$ \\
\hline Saline bolus & $0.61 \pm 1.02$ & $50(33)$ & $91(10)$ & 31 & $0.18(0.12-0.25)$ \\
\hline \multicolumn{6}{|l|}{ Dialysis terminated } \\
\hline early & $0.41 \pm 0.74$ & $43(28)$ & $62(7)$ & 25 & $0.09(0.03-0.14)$ \\
\hline
\end{tabular}

Note: Values expressed as average \pm SD or number (percent) unless noted otherwise. Patients missed 23 dialysis sessions; therefore, data represent 877 dialysis sessions. 
Table 4. Odds Ratios for Intradialytic Symptoms, Signs, Interventions, and Indices of Volume

\begin{tabular}{|c|c|c|c|}
\hline & \multicolumn{3}{|c|}{ Odds Ratios per Unit Change (95\% Confidence Interval) } \\
\hline & UFR Index (mL/h/kg) & $\begin{array}{c}\text { Relative Blood Volume } \\
\text { Slope }(\% / \mathrm{h})\end{array}$ & Volume Index (\%/h/UFR Index) \\
\hline \multicolumn{4}{|l|}{ Symptom/Sign } \\
\hline Cramps & $1.0(0.94-1.05)$ & $1.02(0.88-1.18)$ & $0.92(0.22-3.75)$ \\
\hline Dizziness & $0.97(0.89-1.04)$ & $1.23(0.98-1.55)^{\star}$ & $19.97(1.09-367) \dagger$ \\
\hline Hypotension (<100 mm Hg systolic) & $0.99(0.91-1.06)$ & $1.10(0.91-1.34) \ddagger$ & $3.98(0.53-29.8) \ddagger$ \\
\hline Nausea & $0.96(0.84-1.09)$ & $1.12(0.78-1.61)$ & $2.28(0.12-42.5)$ \\
\hline Headache & $0.98(0.87-1.12)$ & $0.83(0.59-1.17)$ & $1.09(0.07-17.9)$ \\
\hline \multicolumn{4}{|l|}{ Intervention } \\
\hline Trendelenberg position & $1.03(0.87-1.21)$ & $1.72(0.90-3.29) \ddagger$ & $302(1.08-85139) \dagger$ \\
\hline Ultrafiltration reduced & $1.05(0.98-1.14)$ & $1.0(0.82-1.23)$ & $0.22(0.05-1.0) \dagger$ \\
\hline Ultrafiltration stopped & $1.0(0.94-1.06)$ & $1.13(0.95-1.33) \ddagger$ & $3.44(0.71-16.5) \ddagger$ \\
\hline Saline bolus & $1.02(0.95-1.09)$ & $1.04(0.82-1.31)$ & $0.33(0.06-1.8)$ \\
\hline Dialysis terminated early & $1.02(0.95-1.10)$ & $1.19(1.01-1.40) \dagger$ & $5.8(0.86-39.1)^{*}$ \\
\hline
\end{tabular}

Sensitivity and specificity of the 3 markers of volume were calculated for various cutoff values to generate receiver operating characteristic (ROC) curves, including area under the curve and their $95 \%$ confidence intervals (CIs). In an additional analysis, we classified patients to have volume excess if they had volume excess by means of both IVC diameter and collapse criteria, and volume depletion, if they had volume depletion by means of both criteria. ROC curves were also fit for the combined criteria. The ROC curve for UFR index was compared with the ROC curve for RBV and volume index, and reported $P$ were Bonferroni corrected.

All analyses were conducted using SPSS software, version 14.0 (SPSS Inc, Chicago, IL) and Stata 9.0 (Stata Corp, College Station, TX). The reported $P$ are 2 sided and taken to be significant at less than 0.05 .

\section{RESULTS}

Between September 2003 and February 2005, we recruited 150 patients from 4 dialysis units staffed by the nephrology faculty of Indiana University, Indianapolis. In aggregate, 102,693 RBV estimates were available with adequate recordings in each patient.

Clinical characteristics of the 150 patients are listed in Table 2. Ninety percent of participants were black, with cardiovascular disease in approximately half the patients. Average $\mathrm{Kt} / \mathrm{V}$, serum albumin level, and hemoglobin level reflect the general hemodialysis population. Diabetes mellitus was the cause of endstage renal disease in $31 \%$ of patients, and hypertension, in $56 \%$.

\section{Indices of Volume Changes}

Table 1 lists indices of volume. The taxonomic development of RBV models is shown in the

Table 5. Relationship of Volume Indices and Echocardiographic Findings

\begin{tabular}{lccccc}
\hline & $\mathrm{b}(\%)$ & SE b $(\%)$ & $r^{2}$ & SEE & $P$ \\
\hline IVC collapse index & & & & & \\
Ultrafiltration rate index $(\mathrm{mL} / \mathrm{h} / \mathrm{kg})$ & 0.356 & 0.403 & 0.01 & 17.70 & 0.4 \\
Relative blood volume $(\% / \mathrm{h})$ & -2.950 & 0.976 & 0.06 & 17.30 & $<0.01$ \\
Volume index $(\% / \mathrm{h} / \mathrm{mL} / \mathrm{h} / \mathrm{kg})$ & -19.200 & 9.130 & 0.03 & 17.40 & 0.04 \\
IVC end-expiration diameter & $\mathrm{b}(\mathrm{mm})$ & SE b $(\mathrm{mm})$ & $r^{2}$ & SEE & $P$ \\
Ultrafiltration rate index $(\mathrm{mL} / \mathrm{h} / \mathrm{kg})$ & 0.012 & 0.075 & $<0.001$ & 3.31 & 0.9 \\
Relative blood volume $(\% / \mathrm{h})$ & 0.430 & 0.207 & 0.03 & 3.66 & 0.04 \\
Volume index $(\% / \mathrm{h} / \mathrm{mL} / \mathrm{h} / \mathrm{kg})$ & 4.610 & 1.490 & 0.07 & 3.17 & $<0.01$ \\
\hline
\end{tabular}

Abbreviations: b, regression coefficient; SE b, SE of regression coefficient; SEE, mean square error of estimate; IVC, inferior vena cava. 


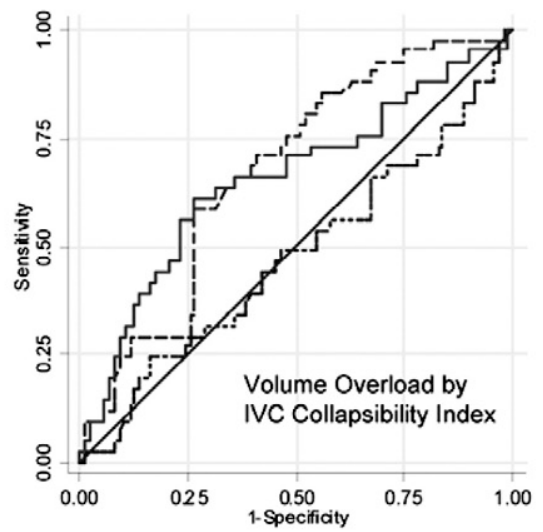

Area Under the Curve $\quad 95 \% \mathrm{Cl} \quad \mathrm{p}$ (vs UFRI)

$\begin{array}{llll}\text { UF Rate Index } & 0.46 & (0.35-0.57) & \\ \text { Relative Blood Volume } & 0.68 & (0.59-0.77) & 0.07 \\ \text { Volume Index } & 0.65 & (0.55-0.76) & 0.03\end{array}$

$\begin{array}{llll}\text { Volume Index } & 0.65 & (0.55-0.76) & 0.03\end{array}$

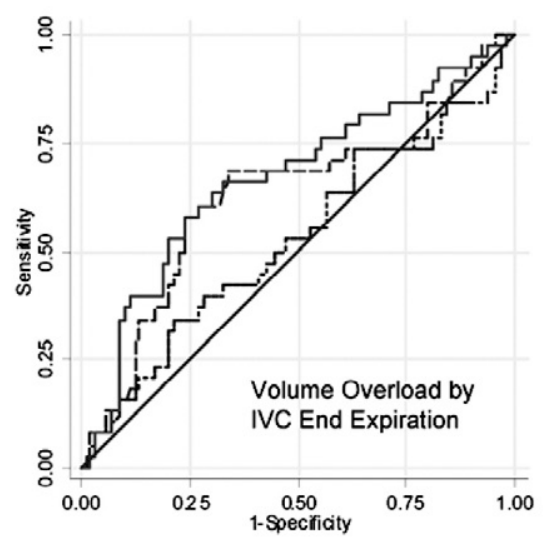

Area Under the Curve $\quad 95 \% \mathrm{Cl} \quad \mathrm{p}$ (vs UFRI)

$\begin{array}{llll}\text { UF Rate Index } & 0.51 & (0.40-0.63) & \\ \text { Relative Blood Volume } & 0.63 & (0.52-0.74) & >0.2 \\ \text { Volume Index } & 0.67 & (0.56-0.77) & 0.19\end{array}$

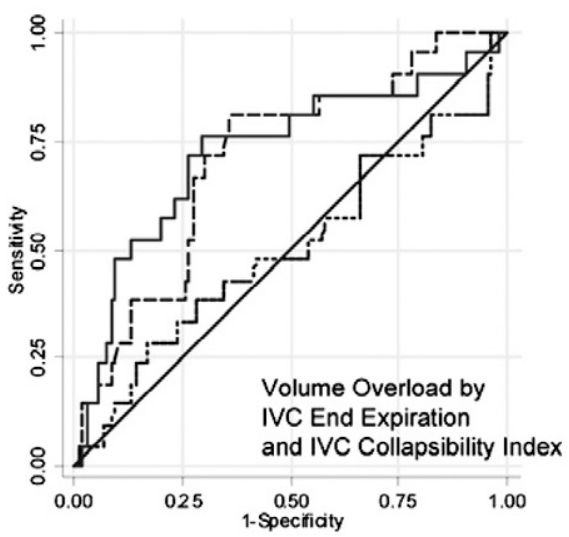

Area Under the Curve $\quad 95 \% \mathrm{Cl} \quad \mathrm{P}$ (vs UFRI)

$\begin{array}{lll}\text { UF Rate Index } & 0.48 \quad(0.33-0.63)\end{array}$

Relative Blood Volume $0.71(0.60-0.83) \quad 0.18$

$\begin{array}{llll}\text { Volume Index } & 0.73 & (0.59-0.86) & 0.04\end{array}$
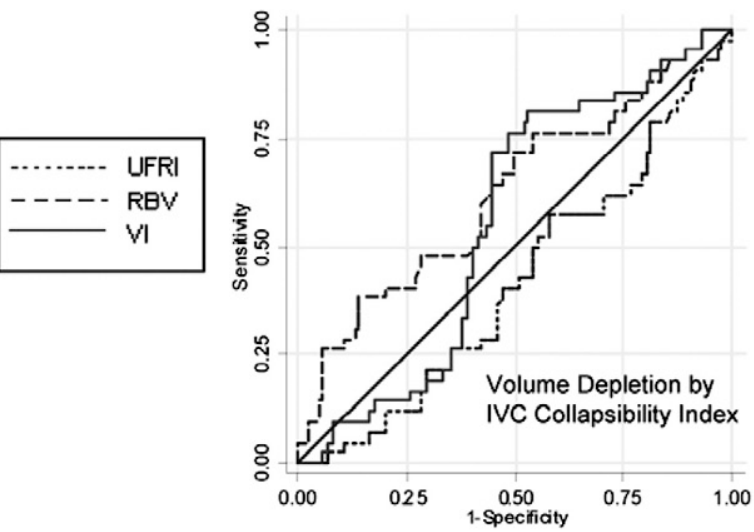

Area Under the Curve $\quad 95 \% \mathrm{Cl} \quad \mathrm{p}$ (vs UFRI)

$\begin{array}{lll}\text { UF Rate Index } & 0.41 \quad(0.31-0.51)\end{array}$

Relative Blood Volume $0.62(0.52-0.72) \quad 0.08$

$\begin{array}{llll}\text { Volume Index } & 0.56 \quad(0.45-0.66) & 0.15\end{array}$

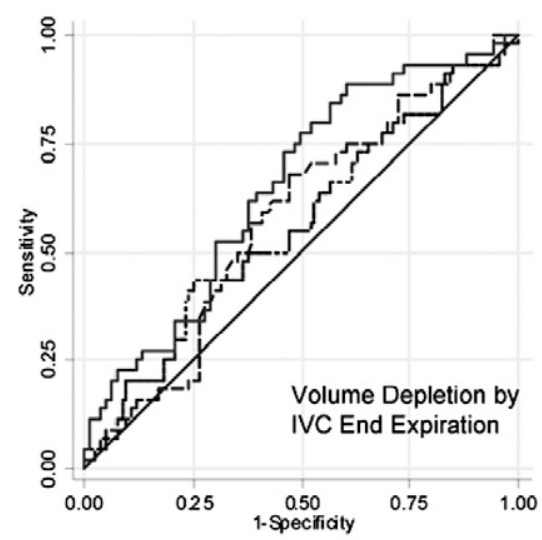

Area Under the Curve $\quad 95 \% \mathrm{Cl} \quad \mathrm{p}$ (vs UFRI)

$\begin{array}{llll}\text { UF Rate Index } & 0.56 & (0.45-0.66) & \\ \text { Relative Blood Volume } & 0.58 & (0.48-0.68) & >0.2 \\ \text { Volume Index } & 0.65 & (0.56-0.75) & >0.2\end{array}$

$\begin{array}{llll}\text { Relative Blood Volume } & 0.58 & (0.48-0.68) & >0.2 \\ \text { Volume Index } & 0.65 & (0.56-0.75) & >0.2\end{array}$

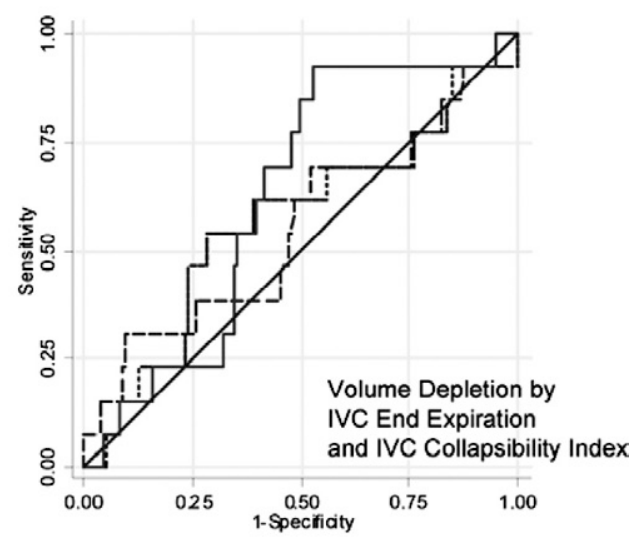

Area Under the Curve $\quad 95 \% \mathrm{Cl} \quad \mathrm{P}$ (vs UFRI)

$\begin{array}{llll}\text { UF Rate Index } & 0.56 & (0.38-0.74) & \\ \text { Relative Blood Volume } & 0.55 & (0.38-0.72) & >0.2 \\ \text { Volume Index } & 0.62 & (0.48-0.76) & >0.2\end{array}$


Appendix. The RBV slope model (model 2) shows that the intercept was close to $100 \%$, as expected, and mean slope was $-2.32 \% / \mathrm{h}$. The volume index model (model 6) shows improved model fit over the RBV model. RBV slope was $-0.255 \% / \mathrm{h} / \mathrm{mL} / \mathrm{h}_{\text {ultrafiltration }} / \mathrm{kg}$ postdialysis weight. Figure 1 shows the relationship of RBV slopes at different levels of UFR index. The top line represents the 10th percentile of UFR index $(3.29 \mathrm{~mL} / \mathrm{h} / \mathrm{kg})$; the middle, the 50th percentile of UFR index $(8.13 \mathrm{~mL} / \mathrm{h} / \mathrm{kg})$; and the bottom, the 90th percentile of UFR index $(13.34 \mathrm{~mL} / \mathrm{h} /$ $\mathrm{kg})$. RBV slopes increase in steepness from the 10th to 90th percentile. The relationship of RBV slope rebound in the last 15 minutes of dialysis when ultrafiltration is stopped is shown in the right panel. These rebound data were available for only 105 patients. The top line represents the 10th percentile; the middle, the 50th percentile; and the bottom, the 90th percentile of UFR index. For patients in the 90th percentile, the intercept is lower and the rebound is steeper. For patients in the 10th percentile, the intercept is higher and the rebound is less steep. Volume index rebound was $0.558 \% / \mathrm{h}(95 \%$ CI, 0.262 to $0.853 ; P<0.001)$.

\section{Relationship Between Symptoms/ Interventions and Markers of Volume}

Table 3 lists the 2-week prevalence of symptoms of hypotension and interventions. Cramps were the most common symptom, followed by dizziness, nausea, and headache. Hypotension, symptomatic or not, was experienced by $47 \%$ of participants. Ultrafiltration needed to be stopped in $45 \%$ of participants, and placement in Trendelenberg position was required in $3 \%$. Cramps complicated $19 \%$ of dialysis treatments, and placement in Trendelenberg position, only less than $1 \%$. The percentage of dialysis sessions complicated by events was remarkably similar across symptoms and interventions for hypotension-related symptoms, which varied from $22 \%$ to $43 \%$. Intraclass correlation coefficients were all greater than zero, indicating a propensity to have events within individuals.

Table 4 lists relationships among dialysisrelated hypotension, its symptoms, and interventions. These interventions represent what occurred during 6 dialysis treatments, not the one associated with RBV monitoring alone. The odds of having hypotension-related symptoms or interventions did not depend on UFR indices. RBV slopes had marginal significance for multiple parameters, but achieved statistical significance for only early termination of hemodialysis. Conversely, volume index was significant for 3 signs and symptoms or intervention.

\section{Relationship Between Echocardiographic Findings and Markers of Volume}

IVC end-expiration diameter averaged $8.7 \pm$ 3.7 (SD) $\mathrm{mm}$, and IVC collapse index was $31.1 \% \pm 17.9 \%$. Table 5 lists bivariate relationships between volume indices and echocardiographic markers of volume. UFR index was not predictive of volume markers. RBV and volume index significantly predicted both IVC endexpiration diameter and collapse index.

Figure 2 shows ROC curves for the diagnosis of volume overload (left panel) or volume depletion (right panel). UFR index was not able to discriminate volume overload by using IVC collapsibility index. Conversely, RBV slope and volume index were both able to detect volume overload. Nonetheless, volume index, not RBV slope model, was significantly superior to UFR index. UFR index was not able to detect volume overload by using IVC end-expiration diameter, but both RBV slope and volume index were significant in detecting volume overload.

Volume overload was diagnosed by using combined criteria of IVC end-expiration and IVC collapsibility index in $18 \%$ of patients. Using the combined criteria, both RBV and volume index

Figure 2. Receiver operating characteristic curve of 3 markers of volume (ultrafiltration [UF] rate index [UFRI], relative blood volume [RBV], and volume index [VI]) and the presence of echocardiographic volume excess (left) by means of inferior vena cava (IVC) collapsibility index (top), end-expiratory diameter (middle), or the combination of the 2 criteria. $\mathrm{VI}$, but not RBV, was significantly better than UFRI for echocardiographic collapsibility index criteria or combined criteria. (Right) Diagnostic performance of each of the 3 markers for volume depletion. None of the markers were very effective in diagnosing volume depletion. The diagonal straight line at $45^{\circ}$ indicates a hypothetical test with no predictive value. Area under the curve for each of the curves and their $95 \%$ confidence intervals (Cls) are shown below each graph and compared with UFRI. $P$ values are Bonferroni corrected. 
were of diagnostic significance. However, only volume index was statistically superior to UFR index. Volume index flatter than 0.221 was $76 \%$ sensitive and $70 \%$ specific in diagnosing volume overload. None of the indices was very effective in diagnosing volume depletion (right panel, Fig 2).

\section{DISCUSSION}

The major findings of our study are that RBV slope corrected for UFR and body weight (ie, the volume index) and RBV slope obtained by means of continuous blood volume monitoring are potential markers of the volume state. The volume index and RBV slopes are markers of dialysis signs, symptoms, and interventions. Both indices, volume index and RBV slopes, were markers of echocardiographic volume overload, but not volume depletion.

Continuous blood volume monitoring has received considerable attention as a marker of volume state. For example, Mitra et $\mathrm{al}^{30}$ proposed that departure of RBV slope from linearity correlated with departure from dry weight. Although these data were rigorously analyzed, application of these results is difficult at the bedside. Furthermore, no information was derived from these parameters proposed by Mitra et $\mathrm{al}^{30}$ regarding when the patient was "too dry." In consideration of this, we modeled our data without transformation, such that our data can be used at the patient's bedside. The taxonomy of models shows that ultrafiltration volume, body weight, and duration of dialysis were each important to improve the model fit (Table 6). RBV slopes corrected for UFR index (UFR divided by postdialysis weight) provided the volume index, which had the best model fit (Table 6, model 6).

UFR index did not predict any symptom, sign, or hypotension-related intervention. RBV slopes were not predictive of any sign or symptom, but achieved statistical significance for early termination of dialysis treatment. Volume index was predictive of dizziness, placement in Trendelenberg position, and reduction in ultrafiltration. Our data are consistent with previous observations reviewed by Dasselaar et al. ${ }^{24}$ Andrulli et $\mathrm{al}^{23}$ noted that when symptomatic hypotension occurred, RBV reduction was not significantly different from that recorded at the same time during hypotension-free sessions. They found no difference in decreases in RBV in normotensive, hypotension-prone, and hypertensive patients and also no critical RBV level for the appearance of symptomatic hypotension. Whether a better model fit and stronger association of volume index with signs and symptoms will translate into it being a better marker of volume overload and subsequent outcomes will need to be determined in future studies.

Volume index ROC curve had an area under the curve of 0.73 . Interpretation of the value of area under the curve of 0.73 is as follows: if 2 hemodialysis patients had IBVM and volume index was used to make a diagnosis of volume overload, using the gold standard of echocardiograms, volume index would be right $73 \%$ of the time. The $95 \%$ CI indicates that the test will be right $56 \%$ to $86 \%$ of the time. The likelihood ratio for volume overload when slope was greater than $-0.221 \% / \mathrm{h} / \mathrm{mL} / \mathrm{h}_{\text {ultrafiltration }} / \mathrm{kg}$ was 2.6 . This means that patients with slopes flatter than $0.221 \% / \mathrm{h} / \mathrm{mL} / \mathrm{h}_{\text {ultrafiltration }} / \mathrm{kg}$ were 2.6 times as likely to have volume overload compared with those with values less than this threshold. The likelihood ratio of slope steeper than $0.221 \% / \mathrm{h} /$ $\mathrm{mL} / \mathrm{h}_{\text {ultrafiltration }} / \mathrm{kg}$ was 0.33 . This means that patients with slopes steeper than 0.221 were one third as likely to have volume overload compared with those with slopes flatter than 0.221. In other words, the chances of not having volume overload was 3 times as high as having volume overload if volume index slopes were steeper than 0.221 .

Taken together, our data suggest that volume index is a marker of latent volume that contributes to plasma refill. It follows that when plasma refill rates are low, volume index becomes steeper, which, if treated with a decrease in ultrafiltration or increase in sodium conductivity, may result in flattening of the volume index. Data accumulated from the use of blood volume tracking technologies show that modulation of ultrafiltration or sodium conductivity can improve hemodynamic stability in comparison to standard dialysis. ${ }^{31}$ Similarly, strategies that increase plasma refill, such as use of the colloid hydroxyethylstarch, can restore RBV more effectively than saline. ${ }^{19}$

Some limitations of our study must be addressed. First, IBVM assumes that uniform mixing of red blood cells occurs throughout the vascular space. However, the distribution of he- 
Table 6. Taxonomy of Models for RBV

\begin{tabular}{|c|c|c|c|c|c|c|}
\hline & \multicolumn{6}{|c|}{ Model } \\
\hline & 1 & 2: RBV Slope & 3 & 4 & 5 & 6: Volume Index \\
\hline Parameter & Uncond Means & Time & UF + Time & UF + Time + Weight & $\begin{array}{c}\text { UF }+\underset{\text { Duration }}{\text { Time }}+\text { Weight }+ \\
\text { Dute }\end{array}$ & Volume Index \\
\hline Intercept & $95.1(94.6-95.6)^{\star}$ & $99.3(99.0-99.6)^{\star}$ & $99.2(98.5-99.9)^{\star}$ & $99.6(98.3-101.0)^{\star}$ & $98.1(95.8-100.6)^{\star}$ & $99.2(98.5-100.0)^{\star}$ \\
\hline Slope (\%/h) & & $-2.32(-2.56 \text { to }-2.08)^{\star}$ & $-0.76(-1.24$ to -0.28$) \dagger$ & $-2.32(-3.20 \text { to }-1.44)^{\star}$ & $-3.79(-5.33 \text { to }-2.26)^{\star}$ & $-0.19(-0.66-0.28)$ \\
\hline UF Intercept (\%) & & & $0.01(-0.23-0.25)$ & $0.08(-0.18-0.35)$ & $-0.01(-0.30-0.28)$ & \\
\hline UF slope (\%/h/L) & & & $-0.61(-0.77 \text { to }-0.44)^{\star}$ & $-0.76(-0.93 \text { to }-0.58)^{*}$ & $-0.87(-1.06 \text { to }-0.69)^{\star}$ & \\
\hline \multicolumn{7}{|l|}{ Postdialysis weight } \\
\hline intercept (\%) & & & & $-0.01(-0.03-0.01)$ & $-0.01(-0.03-0.01)$ & \\
\hline \multicolumn{7}{|l|}{ Postdialysis weight } \\
\hline slope $(\% / \mathrm{h} / \mathrm{L} / \mathrm{kg})$ & & & & $0.025(0.013-0.036)^{*}$ & $0.023(0.011-0.035)^{\star}$ & \\
\hline Duration intercept (\%) & & & & & $0.46(-0.19-1.10)$ & \\
\hline \multicolumn{7}{|l|}{ Duration slope $(\% / \mathrm{h} / \mathrm{L} /$} \\
\hline kg/h dialysis) & & & & & $0.483(0.074-0.892) \ddagger$ & \\
\hline UFR index intercept (\%) & & & & & & $0.0(-0.08-0.08)$ \\
\hline $\begin{array}{l}\text { UFR index slope }(\% / \mathrm{h} / \\
\text { (L/kg/h) dialysis } \\
\text { duration) }\end{array}$ & & & & & & $-0.255(-0.306 \text { to }-0.203)^{*}$ \\
\hline$\sigma$ & 8.897 & 0.940 & 0.944 & 0.947 & 0.955 & 0.955 \\
\hline Pseudo $R^{2}$ & & 0.989 & 0.989 & 0.989 & 0.988 & 0.988 \\
\hline & 490828 & 272994 & 266048 & 264868 & 260078 & 260076 \\
\hline \multirow{8}{*}{ Model comparison } & & $2 v 1$ & $3 v 1$ & $4 v 1$ & $5 v 1$ & $6 v 1$ \\
\hline & & $P<0.001$ & $P<0.001$ & $P<0.001$ & $P<0.001$ & $P<0.001$ \\
\hline & & & $3 v 2$ & $4 v 2$ & $5 v 2$ & $6 v 2$ \\
\hline & & & $P<0.001$ & $P<0.001$ & $P<0.001$ & $P<0.001$ \\
\hline & & & & $4 v 3$ & $5 \vee 3$ & \\
\hline & & & & $P<0.001$ & $P<0.001$ & \\
\hline & & & & & $5 v 4$ & \\
\hline & & & & & $P<0.001$ & \\
\hline
\end{tabular}

Note: Because models were nested, comparisons of goodness of fit between models were tested by improvement in the log-likelihood using a chi-square test. All models use RBV as the dependent variable. Independent variables are listed in "Parameter" row. All 150 patients had measurements of RBV and were used in the models.

Abbreviations: RBV, relative blood volume; UFR, ultrafiltration rate; LL, log-likelihood.

${ }^{\star} P<0.001$

$\dagger P<0.01$

$\ddagger P<0.05$. 


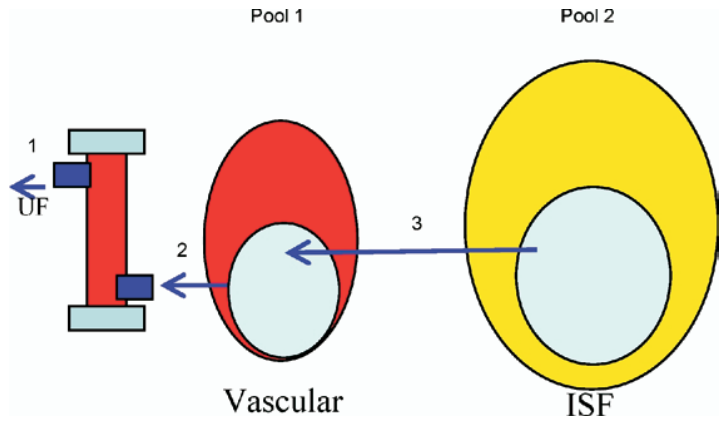

Figure 3. Model of the volume index. See text for details. Abbreviations: UF, ultrafiltration; ISF, interstitial fluid.

matocrit in the central circulation and microcirculation may not be constant and may change during episodes of hypotension. ${ }^{32}$ Second, clinical and echocardiographic findings are not validated measures of volume. Third, results are not adjusted for demographic or clinical characteristics. Fourth, the majority of patients in our study were black. Whether these data are applicable to nonblacks is uncertain. Accordingly, performance characteristics of the indices may differ across populations. Fifth, although our study provides population parameters of volume index, the optimal volume index associated with the best outcomes is not known. Also, whether the decrease in blood volume with dialysis or rebound of blood volume after dialysis should be used to dictate therapy is unclear. Additional data need to be prospectively gathered that associate clinically relevant outcomes with rates of blood volume decrease with dialysis.

Volume index averaged approximately $-0.25 \% /$ $\mathrm{h} / \mathrm{mL} / \mathrm{h}_{\text {ultrafiltration }} / \mathrm{kg}$. Because most patients are dialyzed for 4 hours, it follows that volume change during dialysis would be approximately the UFR index in percent. Thus, a patient with an ultrafiltration volume of $4,000 \mathrm{~mL}$ who is dialyzed for 4 hours and weighs $100 \mathrm{~kg}$ after dialysis would have a UFR index of $4,000 / 4 / 100$, or $10 \mathrm{~mL} / \mathrm{kg} / \mathrm{h}$, and an expected $10 \%$ change in RBV during a treatment. If this patient has a $2 \%$ change in RBV during 4 hours, it is likely that this patient has volume overload by means of echocardiography and is less likely to experience hypotension-related signs and symptoms. The volume index thus can give a qualitative sense of excess vascular volume in hemodialysis patients.
In a previous randomized controlled trial, IVBM was not useful in guiding volume reduction therapies. ${ }^{33,34}$ In children on hemodialysis therapy, this IVBM led to better outcomes. ${ }^{35}$ Perhaps therapy guided by using volume index may serve as a better tool to prescribe sodium reduction therapy in dialysis patients. Volume index appears to be a novel marker of volume, but requires validation studies, and its utility needs to be tested in clinical trials. Future studies should address the impact of this simple index on quality of life and cardiovascular outcomes.

\section{ACKNOWLEDGEMENTS}

We thank the members of the dialysis units at Dialysis Clinics Inc, Clarian Health, the Roudebush VA Medical Center, and the faculty of the Division of Nephrology, who allowed us to study their patients.

Support: This study was supported by Grant 5RO1NIDDK062030-05 from the National Institutes of Health.

Financial Disclosure: None.

\section{REFERENCES}

1. Saad E, Charra B, Raj DS: Hypertension control with daily dialysis. Semin Dial 17:295-298, 2004

2. Charra B, Laurent G, Chazot C, et al: Clinical assessment of dry weight. Nephrol Dial Transplant 11:S16-S19, 1996 (suppl 2)

3. Dorhout Mees EJ: Volaemia and blood pressure in renal failure: Have old truths been forgotten? Nephrol Dial Transplant 10:1297-1298, 1995

4. Kouw PM, Kooman JP, Cheriex EC, et al: Assessment of postdialysis dry weight: A comparison of techniques. J Am Soc Nephrol 4:98-104, 1993

5. Ishibe S, Peixoto AJ: Methods of assessment of volume status and intercompartmental fluid shifts in hemodialysis patients: Implications in clinical practice. Semin Dial 17:37-43, 2004

6. Leypoldt JK, Cheung AK: Evaluating volume status in hemodialysis patients. Adv Ren Replace Ther 5:64-74, 1998

7. Charra B, Chazot C: Volume control, blood pressure and cardiovascular function. Nephron Physiol 93:94-101, 2003

8. Khosla UM, Johnson RJ: Hypertension in the hemodialysis patient and the "lag phenomenon": Insights into pathophysiology and clinical management. Am J Kidney Dis 43:739-751, 2004

9. van der Zee S, Thompson A, Zimmerman R, et al: Vasopressin administration facilitates fluid removal during hemodialysis. Kidney Int 71:318-324, 2007

10. Yamamoto N, Sasaki E, Goda K, et al: Treatment of post-dialytic orthostatic hypotension with an inflatable abdominal band in hemodialysis patients. Kidney Int 70:17931800, 2006

11. Imai E, Fujii M, Kohno Y, et al: Adenosine A1 receptor antagonist improves intradialytic hypotension. Kidney Int 69:877-883, 2006 
12. Shoji T, Tsubakihara Y, Fujii M, et al: Hemodialysisassociated hypotension as an independent risk factor for two-year mortality in hemodialysis patients. Kidney Int 66:1212-1220, 2004

13. Inrig JK, Oddone EZ, Hasselblad V, et al: Association of intradialytic blood pressure changes with hospitalization and mortality rates in prevalent ESRD patients. Kidney Int 71:454-461, 2007

14. Coleman TG, Guyton AC: Hypertension caused by salt loading in the dog. 3. Onset transients of cardiac output and other circulatory variables. Circ Res 25:153-160, 1969

15. Fishbane S, Natke E, Maesaka JK: Role of volume overload in dialysis-refractory hypertension. Am J Kidney Dis 28:257-261, 1996

16. Agarwal R: Hypertension and survival in chronic hemodialysis patients-Past lessons and future opportunities. Kidney Int 67:1-13, 2005

17. Saran R, Bragg-Gresham JL, Levin NW, et al: Longer treatment time and slower ultrafiltration in hemodialysis: Associations with reduced mortality in the DOPPS. Kidney Int 69:1222-1228, 2006

18. Pillon L, Piccoli A, Lowrie EG, et al: Vector length as a proxy for the adequacy of ultrafiltration in hemodialysis. Kidney Int 66:1266-1271, 2004

19. Van der Sande FM, Kooman JP, Barendregt JN, et al: Effect of intravenous saline, albumin, or hydroxyethylstarch on blood volume during combined ultrafiltration and hemodialysis. J Am Soc Nephrol 10:1303-1308, 1999

20. Leypoldt JK, Cheung AK, Steuer RR, et al: Determination of circulating blood volume by continuously monitoring hematocrit during hemodialysis. J Am Soc Nephrol 6:214-219, 1995

21. Steuer RR, Bell DA, Barrett LL: Optical measurement of hematocrit and other biological constituents in renal therapy. Adv Ren Replace Ther 6:217-224, 1999

22. Steuer RR, Leypoldt JK, Cheung AK, et al: Reducing symptoms during hemodialysis by continuously monitoring the hematocrit. Am J Kidney Dis 27:525-532, 1996

23. Andrulli S, Colzani S, Mascia F, et al: The role of blood volume reduction in the genesis of intradialytic hypotension. Am J Kidney Dis 40:1244-1254, 2002

24. Dasselaar JJ, Huisman RM, de Jong PE, et al: Measurement of relative blood volume changes during haemodialysis: Merits and limitations. Nephrol Dial Transplant 20: 2043-2049, 2005

25. Steuer RR, Germain MJ, Leypoldt JK, et al: Enhanced fluid removal guided by blood volume monitoring during chronic hemodialysis. Artif Organs 22:627-632, 1998

26. Lopot F, Kotyk P, Blaha J, et al: Use of continuous blood volume monitoring to detect inadequately high dry weight. Int J Artif Organs 19:411-414, 1996

27. Jaeger JQ, Mehta RL: Assessment of dry weight in hemodialysis: An overview. J Am Soc Nephrol 10:392-403, 1999

28. Cheriex EC, Leunissen KM, Janssen JH, et al: Echography of the inferior vena cava is a simple and reliable tool for estimation of 'dry weight' in haemodialysis patients. Nephrol Dial Transplant 4:563-568, 1989
29. Zeger SL, Liang KY: Longitudinal data analysis for discrete and continuous outcomes. Biometrics 42:121-130, 1986

30. Mitra S, Chamney P, Greenwood R, et al: Linear decay of relative blood volume during ultrafiltration predicts hemodynamic instability. Am J Kidney Dis 40:556-565, 2002

31. Santoro A, Mancini E, Basile C, et al: Blood volume controlled hemodialysis in hypotension-prone patients: A randomized, multicenter controlled trial. Kidney Int 62:10341045,2002

32. Mitra S, Chamney P, Greenwood R, et al: The relationship between systemic and whole-body hematocrit is not constant during ultrafiltration on hemodialysis. J Am Soc Nephrol 15:463-469, 2004

33. Johansen LB, Videbaek R, Hammerum M, et al: Underestimation of plasma volume changes in humans by hematocrit/hemoglobin method. Am J Physiol 274:R126R130, 1998

34. Reddan DN, Szczech LA, Hasselblad V, et al: Intradialytic blood volume monitoring in ambulatory hemodialysis patients: A randomized trial. J Am Soc Nephrol 16:21622169,2005

35. Goldstein SL, Smith CM, Currier H: Noninvasive interventions to decrease hospitalization and associated costs for pediatric patients receiving hemodialysis. J Am Soc Nephrol 14:2127-2131, 2003

36. Singer JD: Using SAS PROC MIXED to fit multilevel models, hierarchical models, and individual growth models. J Educ Behavior Stat 24:323-355, 1998

37. Singer JD, Willett JB: Applied Longitudinal Data Analysis Modeling Change and Event Occurrence. Oxford, UK: Oxford University, 2003

\section{APPENDIX}

To conceptualize volume compartments, we formulated a model to review the physiological characteristics of volume removal during hemodialysis. Figure 3 shows the overall concept of volume developed in this report. The amount of ultrafiltration prescribed, shown by arrow 1, dictates the stress placed on the intravascular volume residing in pool 1. More accurately, it is not ultrafiltration by itself, but UFR, corrected for body weight (a proxy for total-body water), that produces the volume stress. We call this the ultrafiltration index. In response to the UFR index, RBV measured by means of changes in hematocrit in pool 1 and this stress is measured by using RBV slope. RBV slope is a function of fluid removal rate (arrow 2) and plasma refill rate (arrow 3). Adjustment of RBV slope for UFR index would be an index of the plasma refill rate (arrow 3). Because UFR index is known for each patient, RBV slope corrected for UFR index, the volume index, reflects the latent volume pool and 
the ability of this pool to replenish the intravascular compartment.

\section{Data Analysis}

Linear mixed models were used to calculate intercepts and slopes. In this model, the level 1 change describes how each subject changes over time (intraindividual change). More explicitly, a straight-line change model for the individuals was used to model RBV:

(1)

$$
y_{i t}=\pi_{o i}+\pi_{1 i} a_{i t}+\varepsilon_{i t}
$$

where $y_{i t}$ is $\mathrm{RBV}$ for the $i$ th individual $(i=$ $1, \ldots, N)$ at the $t$ th measurement occasion $(t=$ $1, \ldots, T), \pi_{o i}$ is the intercept for the $i$ th individual, $\pi_{1 i}$ is the slope for the $i$ th individual, $a_{i t}$ represents the value of time for the $i$ th individual at the $t$ th measurement occasion, and $\varepsilon_{i t}$ is the error for the $i$ th individual at the $t$ th measurement occasion. $\varepsilon_{i t}$ was assumed to distribute normally and independently with a mean of zero and constant variance across time. The level 2 model describes how these change coefficients (ie, $\pi_{o i}$ and $\pi_{1 i}$ ) differ across people (interindividual change). The covariates of interest were used to model interindividual differences in intraindividual change. More explicitly, each change coefficient in equation 1 is modeled as a dependent variable in another equation:

(2)

$$
\pi_{p i}=\beta_{p 0}+\sum_{k=2}^{K} \beta_{p k} f(X)_{k i}+v_{p i}
$$

where $\beta_{p 0}$ is the intercept for the $p$ th change parameter $(p=0,1), \beta_{p k}$ is the regression coefficient for the $k$ th covariate, $f(X)_{k i}$ is some function of the $X_{k i}$ (possibly the identify function where no transformation of $X$ occurs), and $v_{p i}$ represents the unique effect for the $i$ th individual for the $p$ th change coefficient. Some of the second-level covariates tested were ultrafiltration, duration of dialysis therapy, and postdialysis weight for model development.

To calculate RBV rebound, we log transformed the data before fitting slopes. Results of $\log$ transformed and untransformed data were similar before the termination of ultrafiltration. Therefore, we did not use log-transformed RBV results for the majority of the analyses.

We used a taxonomy of models to describe the optimization of the model fit (Table 6). ${ }^{36,37}$ 